Pathophysiology

of Haemostasis

Pathophysiol Haemost Thromb 2003;33:116-119

Received: November 11, 2002 and Thrombosis

\title{
Laparoscopic Splenectomy for Immune Thrombocytopenic Purpura in Patients with Severe Refractory Thrombocytopenia
}

\author{
Andrei Keidar Boaz Sagi Amir Szold \\ Endoscopic Surgery Service, Department of Surgery 'B', Tel Aviv Sourasky Medical Center, \\ the Sackler Faculty of Medicine, Tel Aviv University, Tel Aviv, Israel
}

\section{Key Words}

Immune thrombocytopenic purpura . Splenectomy · Laparoscopy · Thrombocytopenia

\begin{abstract}
Laparoscopic splenectomy (LS) for immune thrombocytopenic purpura has a success rate of $70-90 \%$. This invasive procedure is sometimes required for patients with refractory thombocytopenia. However, no data on their outcome are available. If the hematologic response is inadequate, its value vis-à-vis the risk associated with major surgery is open to question. Twelve of 110 patients who underwent LS in our institution had a platelet count lower than $20 \times 10^{9} / \mathrm{I}$ (mean $6.6 \times 10^{9} / \mathrm{I}$ ). Nine patients $(75 \%)$ had a good-to-excellent hematologic response. The complication rate was $33 \%$. LS in patients with very low platelet counts is feasible and yields a response rate similar to the average of patients with immune thrombocytopenic purpura. However, it bears a higher perioperative morbidity compared with LS in patients with higher counts.
\end{abstract}

Copyright $@ 2003$ S. Karger AG, Basel

\section{Introduction}

Splenectomy is an effective therapeutic modality for the treatment of immune thrombocytopenic purpura (ITP), with a rate of $70-90 \%$ of hematologic response in patients either refractory to or dependent upon medical treatment [1]. The objective of surgery is to stop/prevent bleeding by eliminating the organ responsible for the clearance of antibody-coated platelets, without treating the underlying pathological process. There are several preparative regimens for preoperatively elevating the thrombocyte count, including high-dose intravenous immunoglobulin (IVIG), high-dose steroids, and transfusion of platelets. The majority of patients respond to medical treatment, while some do not, and because of this refractoriness undergo surgery despite low platelet counts. There are few reports in the literature on the outcome of invasive procedures in thrombocytopenic patients [3, 5], but none on the surgical outcome of this small subgroup of patients when they are operated laparoscopically. Since 1993, we have performed laparoscopic splenectomy (LS) as the procedure of choice for all patients with refractory, relapsing, or steroid-dependent ITP. We prospectively collected the data on all these patients, including those with low platelet counts, and present our findings.

Amir Szold, MD

Endoscopic Surgery Service, Tel Aviv Sourasky Medical Center

6 Weitzmann Street

Tel Aviv 64239 (Israel)

Tel. +972 3 6973911, Fax +972 3 6974682, E-Mail amiki@tasmc.health gov.il 
Table 1. Characteristics of patients with severe thrombocytopenia who underwent LS for immune thrombocytopenic purpura

\begin{tabular}{rllcllr}
\hline $\begin{array}{l}\text { Patient } \\
\text { No. }\end{array}$ & $\begin{array}{l}\text { Age } \\
\text { years }\end{array}$ & Sex & $\begin{array}{l}\text { Disease } \\
\text { duration } \\
\text { months }\end{array}$ & Prior therapy & $\begin{array}{l}\text { Perioperative } \\
\text { platelet } \\
\text { transfusion }\end{array}$ & $\begin{array}{l}\text { Preoperative } \\
\text { platelet count } \\
\times 10^{9} / \mathrm{ml}\end{array}$ \\
\hline 1 & 55 & F & 24 & Dex, P, IG & - & 2 \\
2 & 31 & M & 1.5 & P, IG & 7 & 6 \\
3 & 32 & M & 1 & P, Dex, IG, Vin & - & 18 \\
4 & 60 & F & 240 & P, IG, Dex & 6 & 6 \\
5 & 72 & F & 2 & P, Dex, Vin, danazol & 22 & 1 \\
6 & 18 & M & 120 & P, IG & 10 & 1 \\
7 & 79 & F & 1 & P, Dex & 10 & 12 \\
8 & 16 & M & 84 & P, Dex & 6 & 1 \\
9 & 27 & M & 2 & P, IG, Vin & 6 & 3 \\
10 & 79 & F & 120 & P, IG & - & 20 \\
11 & 16 & M & 24 & P, IG & - & 5 \\
12 & 39 & M & 8 & Dex, P & -2 & 5 \\
\hline
\end{tabular}

Dex = Dexamethasone, $\mathrm{P}=$ prednisone; $\mathrm{IG}=$ immunoglobulin; Vin = vincristine.

\section{Materials and Methods}

\section{Patients}

All the patients in this study were diagnosed as having ITP according to the guidelines of the American Society of Hematology [1]. Other causes of thrombocytopenia were ruled out by bone marrow aspiration. Indications for splenectomy were thrombocytopenia with bleeding manifestations (melena, progressive purpura, and recurrent epistaxis) and/or lack of response to conservative treatment, and low platelet counts while on massive steroid and/or immunoglobulin therapy. All patients were offered a laparoscopic procedure.

\section{Preparation}

The patients were given a polyvalent pneumococcal vaccine (Pasteur Merieux, Lyon, France) at least 2 weeks before surgery. They also received IVIG (Sandoglobulin, $0.4 \mathrm{~g} / \mathrm{kg} /$ day for 5 days) or oral high-dose dexamenthasone ( $40 \mathrm{mg} /$ day for 4 days) [6] or both. Three refractory patients were treated with vincristine (table 1$)$.

\section{Operative Technique}

We used the standard surgical technique for LS described in detail elsewhere [4]. Briefly, the operation is performed under general anesthesia with the patient in the right lateral position. This position allows a good visualization of the operative field with almost no need for any further retraction and a very good exposure of the short gastric vessels. The procedure is performed through three or four 5 - to 10 -mm incisions. The abdomen is insufflated with $\mathrm{CO}_{2}$ and 3 laparoscopic ports are introduced to allow a laparoscope and surgical instruments into the abdominal cavity. The procedure is begun after a thorough search for accessory spleens has been made. Then, the splenic flexure of the colon is dissected and the greater omentum is opened. After the anterior aspect of the hilum is exposed, the short gastric vessels are divided. The left upper paracolic space is dissected and the spleen is separated from the kidney and diaphragm, save the last posterior attachments of the upper pole. At this point, the spleen remains attached almost exclusively by vascular supply and the gap between the splenic hilum and tail of the pancreas becomes enlarged. The spleen is now lifted and an endoscopic stapling device is used to divide the hilum. This usually requires one or two applications of the instrument. The final attachments to the diaphragm are incised with coagulating scissors. The spleen is then placed in a sealed plastic bag, the opening of which is drawn through the most lateral port. The opening of the bag is held firmly outside the abdomen and the spleen is crushed using a regular ring clamp and a powerful suction device. After the spleen has been removed, the operative field is irrigated with lactated Ringer's solution, and the site is again inspected for bleeding and reconfirmation that there is no accessory spleen.

\section{Postoperative Management}

Oral intake was started on the first postoperative day. After discharge from hospital, the patients were followed-up first in the surgical and then in the hematological outpatient clinic. All the data on the operative and postoperative course were collected prospectively and entered into the computerized database.

The response to splenectomy was measured by the platelet count as follows: $>150 \times 10^{9} / 1=$ excellent, $50-150 \times 10^{9} / 1=$ good, and $<50 \times 10^{9} / 1=$ no response.

\section{Results}

Of the 110 patients who underwent LS for ITO in our institution between May 1995 and May 2001, 12 (11\%) had a preoperative platelet count $<20 \times 10^{9} / 1$. There were 5 females and 7 males whose mean age was 43 years 
Table 2. Postoperative LS outcome

\begin{tabular}{|c|c|c|c|c|c|}
\hline $\begin{array}{l}\text { Patient } \\
\text { No. }\end{array}$ & $\begin{array}{l}\text { Platelet count } \\
\times 10^{9} / \mathrm{ml}\end{array}$ & $\begin{array}{l}\text { Hospital } \\
\text { stay, days }\end{array}$ & Complication & $\begin{array}{l}\text { Postoperative } \\
\text { blood/platelet } \\
\text { transfusion }\end{array}$ & $\begin{array}{l}\text { Response to } \\
\text { LS }\end{array}$ \\
\hline 1 & 2 & 17 & retroperitoneal hematoma & $3 / 18$ & excellent \\
\hline 2 & 6 & 2 & _- & _- & relapse \\
\hline 3 & 18 & 2 & - & - & excellent \\
\hline 4 & 6 & 7 & - & $2 / 6$ & no response \\
\hline 5 & 1 & 15 & $\begin{array}{l}\text { subphrenic abscess, } \\
\text { urinary tract infection }\end{array}$ & $2 / 10$ & relapse \\
\hline 6 & 1 & 3 & - & - & excellent \\
\hline 7 & 12 & 8 & wound infection & - & excellent $^{1}$ \\
\hline 8 & 1 & 3 & - & - & excellent \\
\hline 9 & 5 & 1 & - & - & excellent \\
\hline 10 & 3 & 3 & - & $2 / 0$ & excellent \\
\hline 11 & 20 & 1 & - & - & $\operatorname{good}^{2}$ \\
\hline 12 & 5 & 2 & - & $2 / 6$ & excellent \\
\hline \multicolumn{6}{|c|}{ Lost to long-term follow-up. } \\
\hline \multicolumn{6}{|c|}{ Expired 2 years after surgery. } \\
\hline
\end{tabular}

(range 16-79). Four (33\%)suffered from additional systemic diseases (e.g. ischemic heart disease, hypertension, or diabetes). Five patients were operated for bleeding tendency (melena, epistaxis, or progressive purpura) that had been unresponsive to maximal therapy, and 7 for refractory very low platelet counts (i.e., $<10 \times 10^{9} / 1$ ). All 12 patients were on chronic steroid treatment (table 1). In addition, 5 patients received IVIG, 4 received pulsed high-dose dexamethasone, and 3 received both. Vincristine had also been administered with no response to 3 patients. The mean count, including patients after platelet transfusion, was $6.6 \times 10^{9} / 1\left(1-20 \times 10^{9} / 1\right.$; table 2$)$. Seven patients with platelet counts $\leq 10 \times 10^{9} / 1$ and 1 patient with $>10 \times 10^{9} / 1$ and bleeding tendency received perioperative platelet transfusions. Since they did not respond with an adequate increment in the platelet count, they were given platelets during the procedure (after the splenic pedicle had been divided when possible). These 8 patients received 8.5 (range 1-22) platelet units perioperatively (table 1).

The operation was completed laparoscopically in all patients with an average operating time of $80 \mathrm{~min}$ (45190). A concomitant laparoscopic left hemicolectomy was performed for an incidental finding of a colonic adenocarcinoma in 1 patient.

Intraoperative bleeding occurred in 2 patients who had platelet counts of $1 \times 10^{9} / 1$ and $5 \times 10^{9} / 1$. They each received 2 units of blood. Three patients (25\%) had post- operative bleeding manifested by lowering of the hemoglobin level and blood collection on imaging studies. Two units of blood were transfused in each of 2 patients with platelet counts of $2 \times 10^{9} / 1$ and $3 \times 10^{9} / 1$, and another patient with a count of $2 \times 10^{9} / 1$ required 3 units of blood. The 5 bleeding patients were also treated with 6-18 units of platelet transfusion (table 2).

There were 4 complications (33\%) in 3 patients: 2 involving fluid collection (1 peripancreatic hematoma and 1 subphrenic abscess) which drained percutaneously, and 2 involving infection (wound and urinary tract) in the third patient. It should be noted that the complication was related to the bleeding in 2 of these patients. The mean length of hospital stay was 5.5 days (range 2-17), and 2 patients were rehospitalized due to complications. There was no surgery-related mortality nor were any reoperations required.

On an average follow-up of 35.5 months (1-68), the hematologic results were as follows: 8 patients had an excellent response $(66.7 \%), 1(8.3 \%)$ had a good response but was lost to follow-up at 1 month after the procedure, 1 patient had no response (8.3\%), and 2 patients (16.7\%) relapsed, one after an initial good response and the other after an excellent response. 


\section{Discussion}

The current recommendations for prophylactic medical therapy before elective splenectomy for ITP are IVIG or oral glucocorticoids with platelet counts $<20 \times 10^{9} / 1$, and platelet transfusion with counts $<10 \times 10^{9} / 1$. These recommendations were established by the American Society of Hematology in 1994 and were based on level V evidence gathered from a literature review [1].

To the best of our knowledge, there are no published data on the surgical (as opposed to hematological) outcome of LS in ITP when performed with low $(<20 \times$ $\left.10^{9} / 1\right)$ or very low $\left(<10 \times 10^{9} / 1\right)$ platelet counts. Despite the consensus that ITP is a benign disease and that most patients with profound thrombocytopenia do not suffer significant bleeding episodes [2,3], there are some patients who are at increased risk of serious morbidity and mortality, and they fall into three categories: death from intracranial hemorrhage, death after splenectomy, and death due to infection after cytotoxic treatments [2]. In our series, there was no mortality, but the morbidity rate associated with the operation was higher than in patients with higher counts, and appears to be related to the degree of thrombocytopenia. If this is the case, it follows that special efforts should be made to elevate the platelet count preoperatively.

The laparoscopic approach ordinarily requires shorter hospital stays and reduces the level of patient discomfort while having an equivalent or lesser rate of intra- and postsurgical complications than an open splenectomy procedure [7]. One of the factors that was believed to preclude successful utilization of LS was bleeding complications, but recent advances in laparoscopic technology have now made it safe to operate on patients with low platelet counts. We found this approach feasible, although the rate of complications was higher $(33 \%)$ and the mean hospital stay was longer (5.5 days) compared with a historical control in which these values were $10 \%$ and 2.3 days, respectively [8]. Data on the outcome of open splenectomy in patients with severe thrombocytopenia are not available for comparison.

As for the hematologic response to splenectomy in patents with very low platelet counts, 9 (75\%) of our patients had an overall good-to-excellent response. Two patients relapsed: one after an excellent initial response (platelet counts after the relapse were around $11 \times 10^{9} / 1$ ), and who died 8 months after the surgery due to an unrelated condition, and another patient with a good initial response who suffered from recurrent epistaxis (his platelet count is currently maintained at $\sim 65 \times 10^{9} / 1$ with prednisone and azathiophrine treatment, with no bleeding). The patient who did not respond bled into the vitreous body, and now has a platelet count of $\sim 5-20 \times$ $10^{9} / 1$ : this patient is receiving no treatment after all possible modalities had been attempted and failed.

In conclusion, the hematologic response to splenectomy in our small cohort of patients with very low platelet counts was close to the known response rate of the patients with a less severe degree of thrombocytopenia. We suggest that LS should be considered a valid therapeutic modality in this group.

\section{Acknowledgement}

Ester Eshkol is thanked for her editorial asisstance.

\section{References}

1 George JN, Woolf SH, Raskob GE, Wasser J, Aledorf LM, Bachem PJ, Blanchette VS, Bussel GB, Cines DB, Kelton GJ, Lichtin DE, McMillan R, Okerbloom JD, Regan DH, Warriel I: Idiopathic thrombocytopenic purpura: A practical guideline developed by explicit methods for the American Society of Hematology. Blood 1996;88:3-40.

2 Schattner E, Bussel J: Mortality in immune thrombocytopenic purpura: Report of seven cases and consideration of prognostic indicators. Am J Hematol 1994;46:120-126.
3 Gural A, Gillis S, Gafanovich A, Israel Z, Wolf D, Pomeranz S, Ben-Yehuda D: Massive intracranial bleeding requiring emergency splenectomy in a patient with CMV-associated thrombocytopenia. Haemostasis 1998;28:250-255.

4 Szold A, Sagi B, Merhav A, Klausner J: Optimizing laparoscopic splenectomy: Technical details and experience in 59 patients. Surg Endosc 1998; 12:1078-1081.

5 Rebulla P: Trigger for platelet transfusion. Vox Sang 2000;78(suppl 2):179-182.
6 Bulvik S, Winder A, Ben-Tal O, Szold A, Eldor A: High-dose dexamethasone for splenectomy in patients with idiopathic thrombocytic purpura. Haemostasis 1998;28:256-259.

7 Lozano-Salazar R, Herrer M, Vargas-Vorackova F, Lopez-Karpovitch X: Laparoscopic versus open splenectomy for immune thrombocytopenic purpura. Am J Surg 1998;176:366369.

8 Szold A, Schwartz J, Abu-Abeid S, Bulvik S, Eldor A: Laparoscopic splenectomies for idiopathic thrombocytopenic purpura: Experience of sixty cases. Am J Hematol 2000;63:7-10. 